\title{
Source of the 70-Day Mesoscale Eddy Variability in the Coral Sea and the North Fiji Basin*
}

\author{
Bo QIU AND SHUIMING CHEN \\ Department of Oceanography, University of Hawaii at Manoa, Honolulu, Hawaii \\ WILLIAM S. KESSLER \\ NOAA/Pacific Marine Environmental Laboratory, Seattle, Washington
}

(Manuscript received 23 January 2008, in final form 16 July 2008)

\begin{abstract}
Large-amplitude sea surface height (SSH) variations with a wave period of 70 days and a wavelength of about $700 \mathrm{~km}$ are detected in the Coral Sea centered along $\sim 16^{\circ} \mathrm{S}$ and in the North Fiji Basin along $\sim 18^{\circ} \mathrm{S}$. These mesoscale eddy signals have a well-defined annual cycle with a maximum in December/January and a minimum in May/June. As the southeasterly trades intercept the island mountains of Vanuatu and Fiji, they generate localized wind stress curl dipoles, which in turn induce the eastward-flowing Coral Sea Countercurrent (CSCC) and Fiji Basin Countercurrent (FBCC) in the Coral Sea and the North Fiji Basin, respectively. The high eddy variability band along $16^{\circ} \mathrm{S}$ is hypothesized in this study as resulting from barotropic instability due to the lateral shear between the eastward-flowing CSCC and its neighboring westward-flowing North Caledonian and North Vanuatu jets (NCJ and NVJ). Based on stability analyses on the background NCJ-CSCC-NVJ system, it is found that the most unstable mode of the system has an equivalent barotropic structure and is insensitive to the specification of the background flow's vertical shear. This barotropic instability hypothesis is also supported by observations; specifically, the Reynolds stresses inferred from the observed SSH data are tilted against the meridional shear of the background NCJ-CSCC-NVJ flow. As the intensity of the NCJ-CSCC-NVJ shear fluctuates with the season, the growth rate of instability changes, resulting in seasonal amplitude modulations in the observed 70-day eddy signals.
\end{abstract}

\section{Introduction}

Accumulation of high-quality sea surface height (SSH) measurements from satellite altimeters since 1992 provides a unique dataset to explore the dynamics governing the time-varying oceanic circulation. It is well known that the oceanic variability is dominated by mesoscale eddy signals with temporal and spatial scales of 50 200 days and 100 500 km, respectively. In the South Pacific Ocean, high mesoscale eddy variability regions include the Antarctic Circumpolar Current band between $50^{\circ}$ and $60^{\circ} \mathrm{S}$, the East Australian Cur-

\footnotetext{
* Pacific Marine Environmental Laboratory Contribution Number 3195.
}

Corresponding author address: Dr. Bo Qiu, Department of Oceanography, University of Hawaii at Manoa, 1000 Pope Road, Honolulu, HI 96822.

E-mail: bo@soest.hawaii.edu rent system in the Tasman Sea, and the South Pacific Subtropical Countercurrent (STCC) band between $20^{\circ}$ and $30^{\circ} \mathrm{S}$ in the western half of the subtropical gyre (Fig. 1a). For each of these three high eddy variability regions, various aspects of the mesoscale eddy properties have been examined with the use of altimetrically derived SSH data (e.g., Morrow et al. 1994; Chelton and Schlax 1996; Qiu and Chen 2004; Bowen et al. 2005; Chiswell et al. 2007; among others). One region where the SSH eddy variability is relatively high, but whose mechanisms have not been diagnosed, is the Coral Sea and the North Fiji Basin in the southwest Pacific Ocean.

As shown in Fig. 1b, a band of relatively high eddy variability, with an rms SSH amplitude exceeding $7 \mathrm{~cm}$, is seen along $\sim 16^{\circ} \mathrm{S}$ in the Coral Sea. In the neighboring North Fiji Basin, a similar band with a lower rms SSH amplitude can be seen along $\sim 18^{\circ} \mathrm{S}$ between Fiji and Vanuatu. Note that this latter eddy variability band along $18^{\circ} \mathrm{S}$ is distinct from the high eddy variability band 

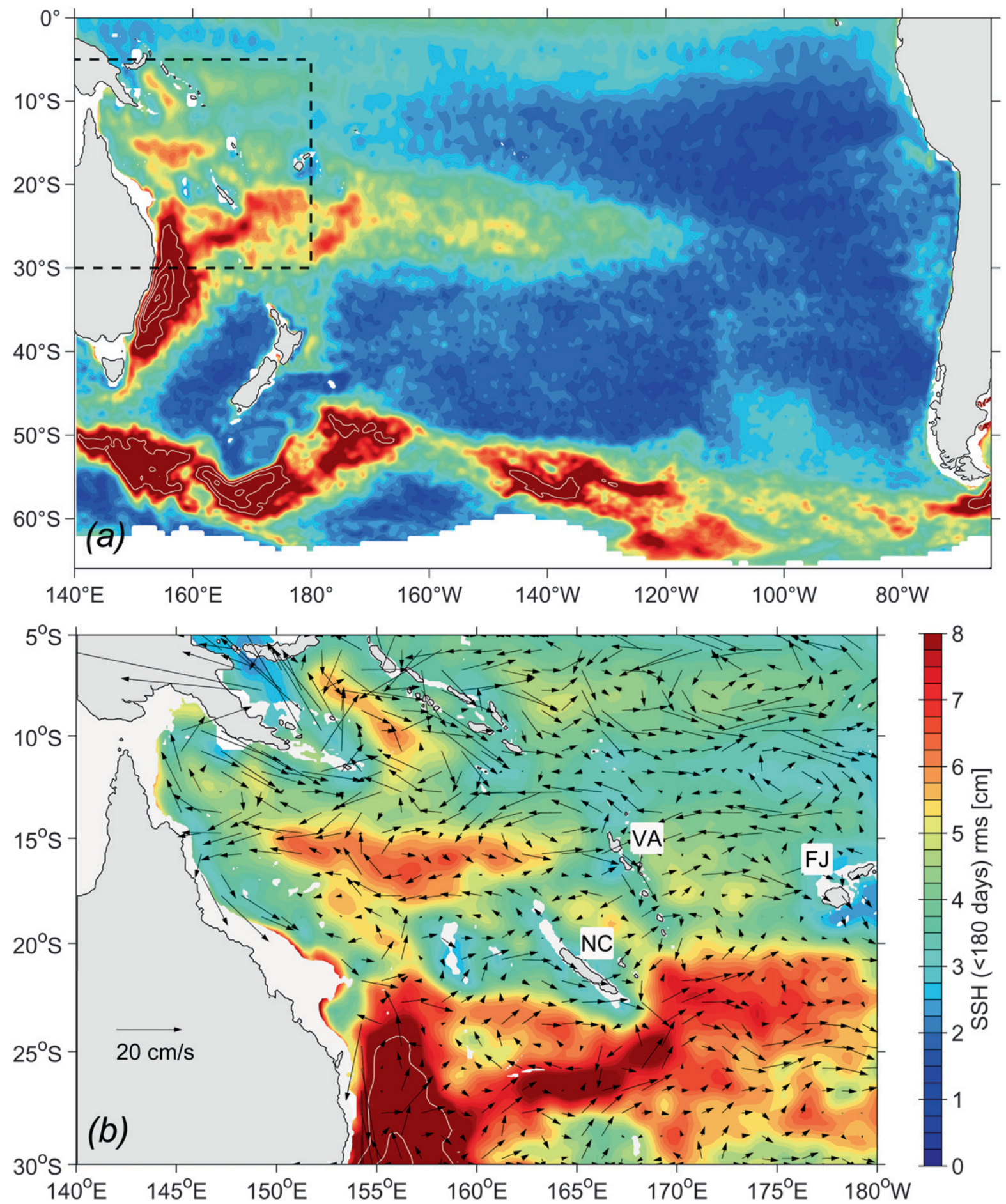

FIG. 1. (a) Rms amplitude of the high-pass-filtered SSH field in the South Pacific Ocean based on weekly Archiving, Validation, and Interpretation of Satellite Oceanographic data (AVISO) data. The high-pass filter has a half-power at 180 days. Thin white lines have a contour interval of $0.05 \mathrm{~m}$ starting from $0.1 \mathrm{~m}$. (b) Same as in (a), except for the regions around the Coral Sea and the North Fiji Basin. Arrows show the surface geostrophic velocity vectors based on the CARS climatology with a reference level at $2000 \mathrm{dbar}$. NC, VA, and FJ stand for New Caledonia, Vanuatu Island, and Fiji Islands, respectively. 
that appears south of $20^{\circ} \mathrm{S}$ and is associated with the South Pacific STCC (e.g., Merle et al. 1969; Roemmich and Cornuelle 1990; Morris et al. 1996).

One unique aspect of the southwest Pacific Ocean is the existence of a series of meridionally aligned islands: Fiji, Vanuatu, and New Caledonia. As the broadscale westward-flowing South Equatorial Current (SEC) encounters these islands, it bifurcates and forms localized zonal jets at the northern/southern tip of the islands. With Fiji, Vanuatu, and New Caledonia staggered east/ west from each other, the island-induced zonal jets merge, further complicating the funneled SEC. The presence of island-induced zonal jets was first noted by Webb (2000) in a $14^{\circ}$-resolution global ocean general circulation model (OGCM). Specifically, Webb identified the North and South Fiji jets (NFJ and SFJ) in the North Fiji Basin, and the North Vanuatu jet (NVJ) and the North and South Caledonian jets (NCJ and SCJ) in the Coral Sea. Since Webb's (2000) study, many studies have confirmed and sharpened the description of these jets in various OGCMs and in situ observations (Stanton et al. 2001; Hughes 2002; Ridgway and Dunn 2003; Kessler and Gourdeau 2006; Gourdeau et al. 2008).

While the interest of the above-mentioned studies has been placed on the westward-flowing, bifurcated SEC jets, a careful look at the surface circulation pattern in the region reveals that the elevated mesoscale eddy signals in both the Coral Sea and the North Fiji Basin are located due west of the Vanuatu and Fiji islands, where the surface geostrophic velocity is, in fact, eastward (see vectors in Fig. 1b). This immediately raises two questions: 1) What is the mechanism responsible for the presence of these eastward-flowing currents in the lee of Vanuatu and Fiji, and 2) Why is the enhanced eddy variability collocated with these eastward-flowing island lee currents, which are weaker in speed than the westward-flowing island jets they separate.

There are three objectives of the present study. The first is to describe the time-mean circulation in the southwest Pacific Ocean, to situate the observed eddy variability in the context of the background currents (section 2). In particular, we argue that the eastwardflowing currents in the lee of Vanuatu and Fiji are induced by localized wind stress curl forcing, which results from the southeast trades impinging on the island mountains. The second objective is to clarify characteristics of the mesoscale eddy variability in the Coral Sea and the North Fiji Basin based on the multiyear satellite altimeter measurements (section 3). In both regions, the eddy SSH signals are dominated by 70 -day oscillations whose amplitudes have a well-defined annual cycle. Our third objective is to explore the mechanism underlying the observed 70-day eddy signals, and for this we focus on the stronger eddy signals in the Coral Sea case (section 4). By adopting both a $2^{1 / 2} 2$ layer and a $1 \frac{1}{2}$-layer reduced-gravity model with observationally constrained zonal-mean flow patterns, we analyze the stability properties of the background flows and clarify the relative importance of the horizontal versus vertical shear of the background flows in contributing to the enhanced eddy variability along $\sim 16^{\circ} \mathrm{S}$. The reduced-gravity model is further used to investigate how changes in the background mean flows modulate the 70-day eddy signals on the seasonal time scale.

\section{Time-mean circulation in the southwest Pacific Ocean}

With the time-mean tropical/subtropical circulation dominated by surface wind forcing, it is useful to start by examining this forcing field. We use the wind data from the European Remote Sensing Satellite (ERS) scatterometer, which were processed into monthly $1^{\circ}$ latitude $\times 1^{\circ}$ longitude gridded fields of stress components by the Centre ERS d'Archivage et de Traitement (CERSAT) and obtained from their Web site (http:// www.ifremer.fr/cersat). Figure 2a shows the mean wind stress (and Fig. 2b its curl) calculated from the $9.5 \mathrm{yr}$ of the ERS data (August 1991 through December 2000) in the southwest Pacific Ocean. In this region, the largescale curl fields are dominated by positive and negative values south and north of $\sim 20^{\circ} \mathrm{S}$, respectively, which delineates the boundary between the wind-driven South Pacific subtropical and tropical gyres. Prominent features that deviate from this large-scale forcing pattern are the two wind stress curl dipoles northwest of Vanuatu and Fiji. A third, weaker curl dipole can be seen to the west of New Caledonia. With the mean surface wind in the region dominated by the southeasterly trades, these dipole patterns are generated as the southeasterly trades intercept the island's mountains.

The Godfrey (1989) Island Rule is a generalized Sverdrup streamfunction that encompasses the blocking effects of islands and the resulting western boundary currents that arise along their coasts (Fig. 2b). Here, the streamfunction is computed from the mean ERS winds, relative to South America, taking into account the islands of Fiji, Vanuatu, New Caledonia, the Solomon Islands, New Zealand, and Australia-New Guinea (see the appendix for more details of the island rule transport estimation). From Fig. 2c, the SEC flow into the Coral Sea between New Caledonia and the Solomon Islands is about $22 \mathrm{~Sv}\left(1 \mathrm{~Sv} \equiv 10^{6} \mathrm{~m}^{3} \mathrm{~s}^{-1}\right)$, occurring in two branches of nearly equal transport, divided by a weak countercurrent in the lee of Vanuatu. The northern branch of the SEC at $10^{\circ}-14^{\circ} \mathrm{S}$, known as the North 

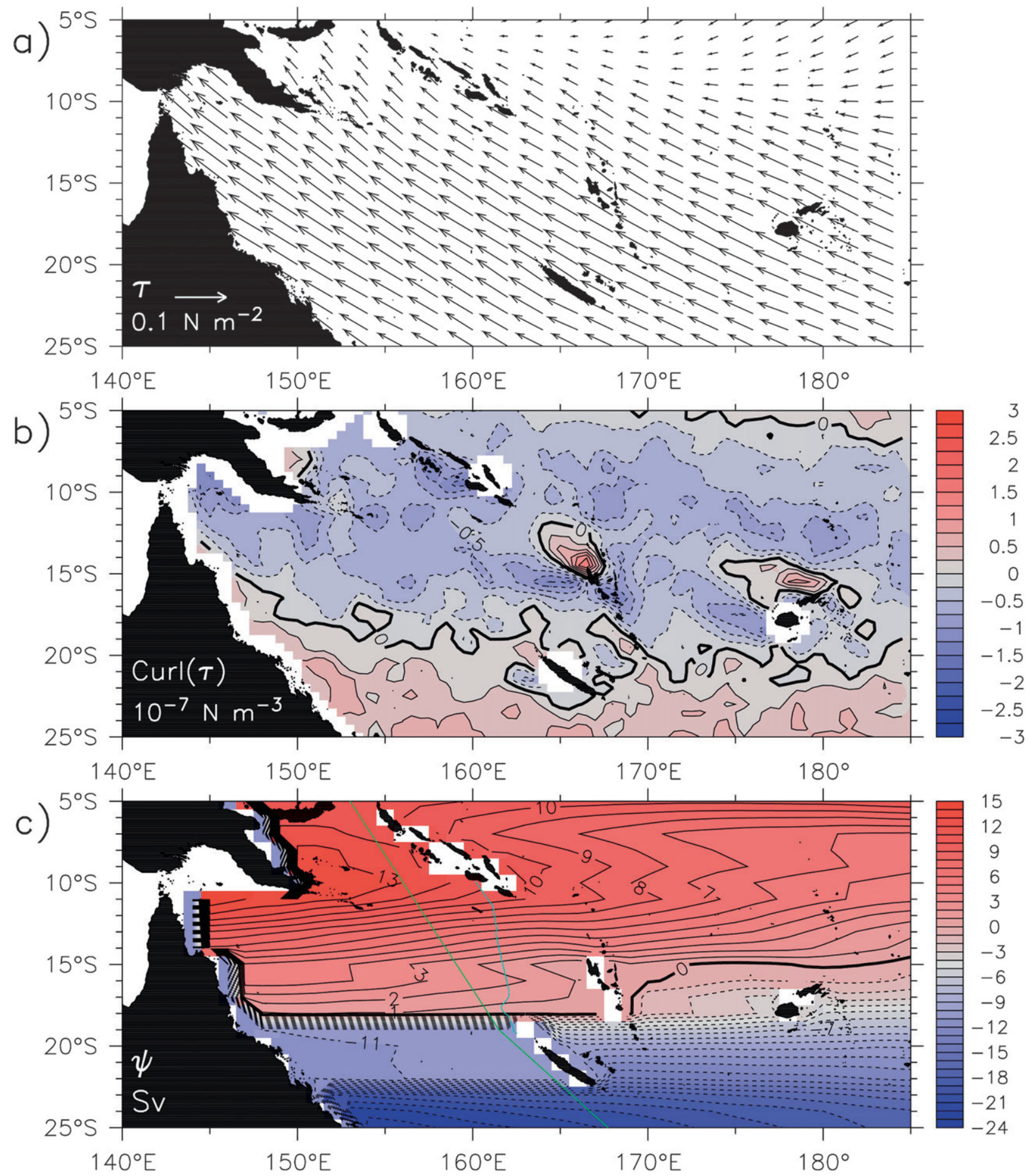

FIG. 2. (a) Mean wind stress vectors from ERS winds over 1991-2000 (scale at bottom left). (b) The wind stress curl ( $\left(10^{-7} \mathrm{~N} \mathrm{~m}^{3}\right)$ based on (a). (c) Sverdrup transport streamfunction $\psi(\mathrm{Sv})$ calculated from Godfrey's Island Rule and the wind stress curl field of (b) (see the appendix).

Vanuatu jet, is relatively broad, while the southern branch, the North Caledonian jet, is seen as the narrow extension of a substantial western boundary current flowing north along the east coast of New Caledonia.
(Note that a nearly continuous shallow reef system extends $200 \mathrm{~km}$ northwest of the island itself.) The winddriven countercurrent at $15^{\circ}-16^{\circ} \mathrm{S}$ has a transport of up to $1 \mathrm{~Sv}$ and extends, gradually weakening, about 
halfway across the Coral Sea; it can appropriately be called the Coral Sea Countercurrent (CSCC). A similar but weaker countercurrent is seen west of Fiji at $17^{\circ}-$ $18^{\circ} \mathrm{S}$, which can be called the Fiji Basin Countercurrent (FBCC).

In both the Coral Sea and North Fiji Basin, the occurrence of a countercurrent is due to the curl dipole produced as the southeast trades divide around the islands' mountains, leaving weaker winds in their lee (Figs. 2a,b). Similar dipoles are observed behind many oceanic islands (Chelton et al. 2004). Under the island rule formulation, the Sverdrup westward integration is restarted at the west coast of an island, with a value that is constant along the entire coast (see the appendix). Thus, any gradients of the transport streamfunction behind an island are due entirely to the local curl. The negative (upwelling) curl patches found west of Fiji and Vanuatu produce narrow ridges of high streamfunction values to their west that have eastward transport on their northern flanks (Fig. 2c).

These structures predicted by the wind are seen in three oceanic datasets. Zonal geostrophic current calculated from the Commonwealth Scientific and Industrial Research Organisation (CSIRO) Atlas of Regional Seas (CARS; Ridgway et al. 2002) at $165^{\circ} \mathrm{E}$ shows the two branches of the SEC divided by a shallow CSCC centered at $15.5^{\circ} \mathrm{S}$ (Fig. 3a). In this relatively smooth climatology, the broader NVJ has larger transport (about $-12 \mathrm{~Sv}$ ) than the NCJ (about $-9 \mathrm{~Sv}$ ), and the CSCC transport is about $1 \mathrm{~Sv}$. The NVJ is associated with the slope of the main thermocline, with weak eastward flow below it, while the NCJ is seen to extend deeper into the water column, and the CSCC is due to a slight upward bend of isotherms above $15^{\circ} \mathrm{C}$, consistent with the upwelling curl west of Vanuatu. Note that the general trend of isotherms spreading toward the south means that geostrophic shear is eastward above about $20^{\circ} \mathrm{C}$, so the westward currents have subsurface maxima.

Cross-track geostrophic currents relative to $400 \mathrm{~m}$ from a frequently repeated expendable bathythermograph (XBT) line, which ran diagonally from the tip of New Caledonia to the eastern Solomon Sea during 1985-2002 (green line in Fig. 2c), also demonstrate two branches of the SEC with a shallow countercurrent between them at $15^{\circ}-17^{\circ} \mathrm{S}$ (Fig. 3b). However, all these currents are weaker than in CARS; although the shallow reference level can account for the too-weak westward currents and too-broad CSCC compared to CARS, this does not explain the smaller magnitude of the CSCC, which probably reflects the fact that the XBT line is a few degrees farther west.

A single section by the Spray glider (Davis et al. 2002; Sherman et al. 2001) was sampled across the SEC from
Guadalcanal to New Caledonia in mid-2005 (Fig. 3c; its trackline is shown as the blue line in Fig. 2c). Glider profiles of temperature and salinity to $600 \mathrm{~m}$ were made at roughly 4-km intervals, and the glider also provides a measure of the vertically averaged absolute velocity, which thus gives the absolute cross-track geostrophic current (Gourdeau et al. 2008). (Because the glider passed close behind the New Caledonia reef south of $18^{\circ} \mathrm{S}$, currents at the southern end of the section cannot be interpreted as representing the large-scale fields.) In this single section, the NVJ and CSCC are comparable to the long-term mean fields in latitude and vertical structure, but with larger magnitude (note the different velocity scales in Fig. 3). However, the NCJ at $17^{\circ} \mathrm{S}$ is seen to be a narrow, nearly barotropic jet; contemporaneous shipboard hydrographic and lowered ADCP data confirm this, showing that the NCJ extends to at least $1750-\mathrm{m}$ depth right at the reef edge, with speeds above $15 \mathrm{~cm} \mathrm{~s}^{-1}$ to $1500 \mathrm{~m}$ (Gourdeau et al. 2008). Transport of the NCJ measured by the glider was about $10 \mathrm{~Sv}$, comparable to CARS and the island rule estimates, but the NVJ transport was almost twice as large. The difference occurs especially in the deep westward current sampled by the glider between $10^{\circ}$ and $11^{\circ} \mathrm{S}$ (Fig. 3c). Thus, with the exception of this westward current near the coast of Guadalcanal, the glider section, though a single realization, appears much like the island rule in its portrayal of the NCJ as a very narrow feature compared to the NVJ. However, though consistent with the wind-driven transport, it is not known why the NCJ extends so much deeper than the other elements of the wind-driven flow.

Thus, the in situ evidence shows that the SEC flowing into the Coral Sea occurs in two westward branches of roughly equal speed, $10-20 \mathrm{~cm} \mathrm{~s}^{-1}$, separated by a shallow countercurrent centered near $15^{\circ}-16^{\circ} \mathrm{S}$. The two westward branches extend at least to the base of the main thermocline, while the CSCC occurs only above about $150 \mathrm{~m}$, with surface speed perhaps half that of the westward jets it divides. All three currents are broadly consistent with a linear wind-driven model that takes the islands into account; in particular, the countercurrent is driven by the wind curl pattern due to the mountains of Vanuatu splitting the southeast trades and the resulting upwelling that extends to the west. A similar but weaker Fiji Basin Countercurrent is found west of Fiji, driven by the same process.

\section{Characteristics of eddy variability from altimeter measurements}

Regions of high eddy variability can be identified in the global SSH anomaly dataset compiled by the Collecte 


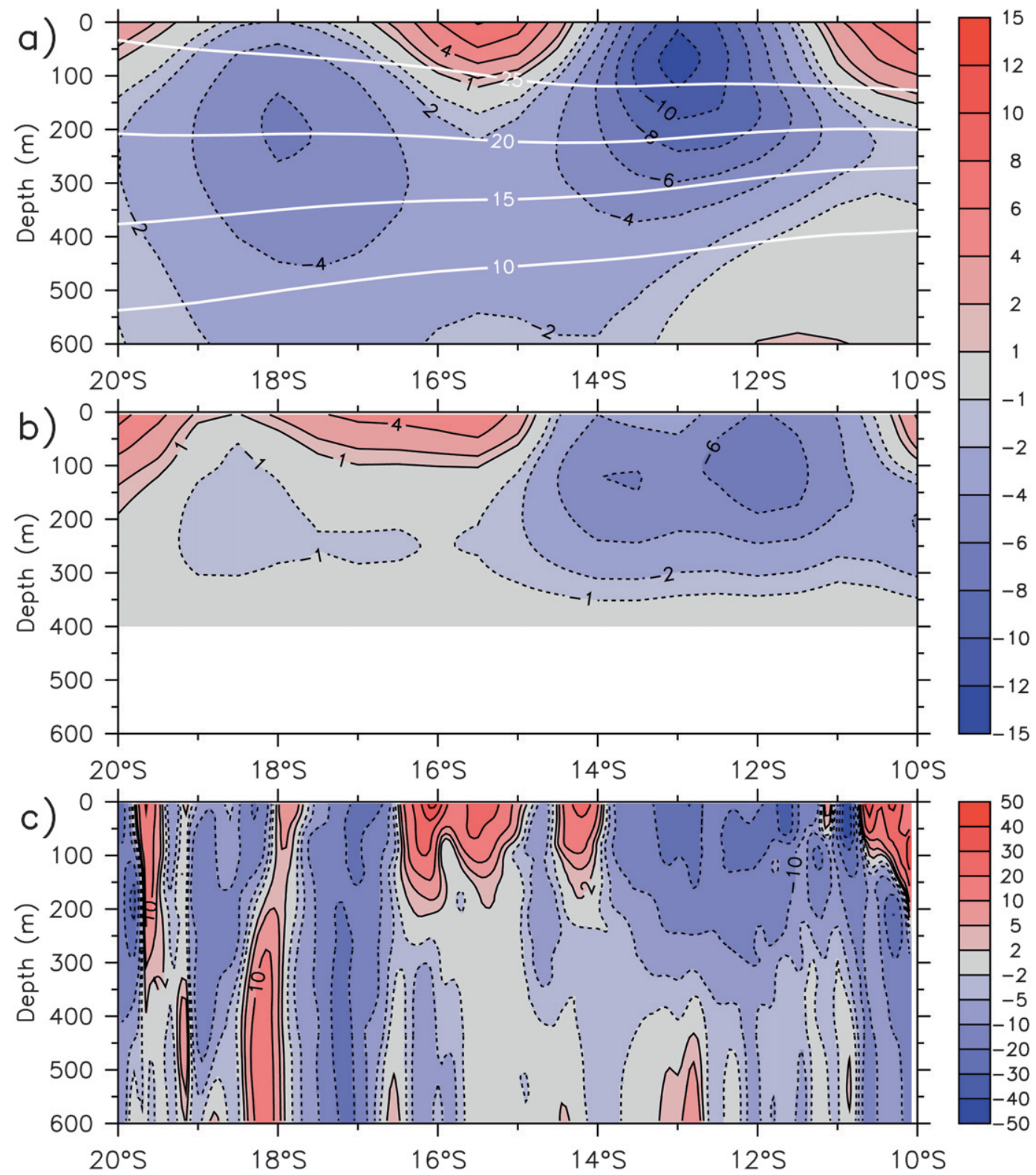

FIG. 3. Zonal and near-zonal geostrophic velocity $\left(\mathrm{cm} \mathrm{s}^{-1}\right)$ along approximately $165^{\circ} \mathrm{E}$ from (a) the CARS climatology, averaged over $160^{\circ}-165^{\circ} \mathrm{E}$; (b) the XBT line, along the green trackline in Fig. 2c, averaged over 1985-2002; (c) the single glider section in 2005, along the blue trackline in Fig. 2c. Red colors indicate eastward velocity, blue westward; the zero contour is omitted. CARS currents are the zonal component, relative to $2000 \mathrm{~m}$, with overlaid $10^{\circ}$, $15^{\circ}, 20^{\circ}$, and $25^{\circ} \mathrm{C}$ isotherms in white. XBT currents are the cross-track components, relative to $400 \mathrm{~m}$. Glider currents are the absolute cross-track geostrophic currents. Note the expanded contour scale as this single, highly resolved section sampled some higher speeds.

Localisation Satellites (CLS) Space Oceanographic Division of Toulouse, France. This dataset merges the Ocean Topography Experiment (TOPEX)/Poseidon, ERS-1/-2, Geosat Follow-On (GFO), and Jason-1 alongtrack SSH measurements and provides improved capability for detecting mesoscale SSH signals (Le Traon et al. 1998; Ducet et al. 2000). It has a 7-day temporal resolution and a $1 / 3^{\circ} \times 1 / 3^{\circ}$ Mercator spatial resolution. Data from the past 14 years, from July 1993 to June 2007, are analyzed in this study.

Figure 4 shows the time-longitude structure of the $\mathrm{SSH}$ anomalies along $16^{\circ} \mathrm{S}$ in the southwest Pacific Ocean from $144^{\circ} \mathrm{E}$ to $170^{\circ} \mathrm{W}$. To emphasize the mesoscale eddy signals, a 180-day high-pass filter has been 


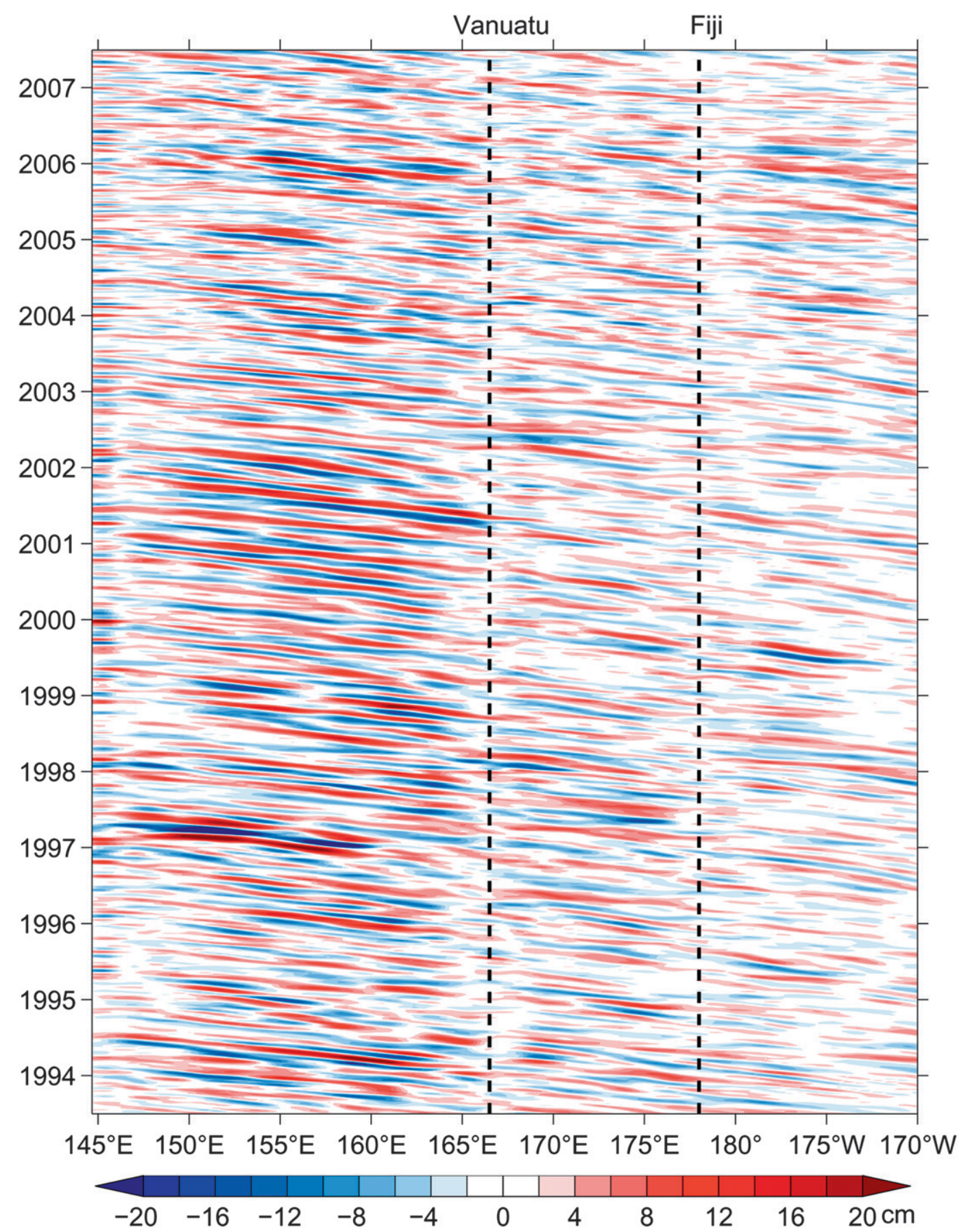

FIG. 4. Time-longitude plot of high-pass-filtered SSH anomalies along $16^{\circ} \mathrm{S}$ in the southwest Pacific Ocean. The high-pass filter has a half-power at 180 days. The two dashed lines denote the locations of Vanuatu and Fiji closest to the $16^{\circ} \mathrm{S}$ parallel.

applied to the original weekly SSH anomaly data. Inside the Coral Sea west of Vanuatu $\left(\sim 167^{\circ} \mathrm{E}\right)$, well-defined positive and negative SSH anomalies appear frequently and tend to propagate westward at a speed of $\sim 0.12$ $\mathrm{m} \mathrm{s}^{-1}$. While some of the SSH anomalies close to Vanuatu may be traced back to the North Fiji Basin east of $167^{\circ} \mathrm{E}$, most of the large-amplitude signals inside the Coral Sea seen in Fig. 4 are locally generated. Inside the North Fiji Basin between Vanuatu and Fiji, the SSH anomalies are not as strong as those in the Coral Sea, but they share the similar characteristics in terms of their westward propagation and local generation. 

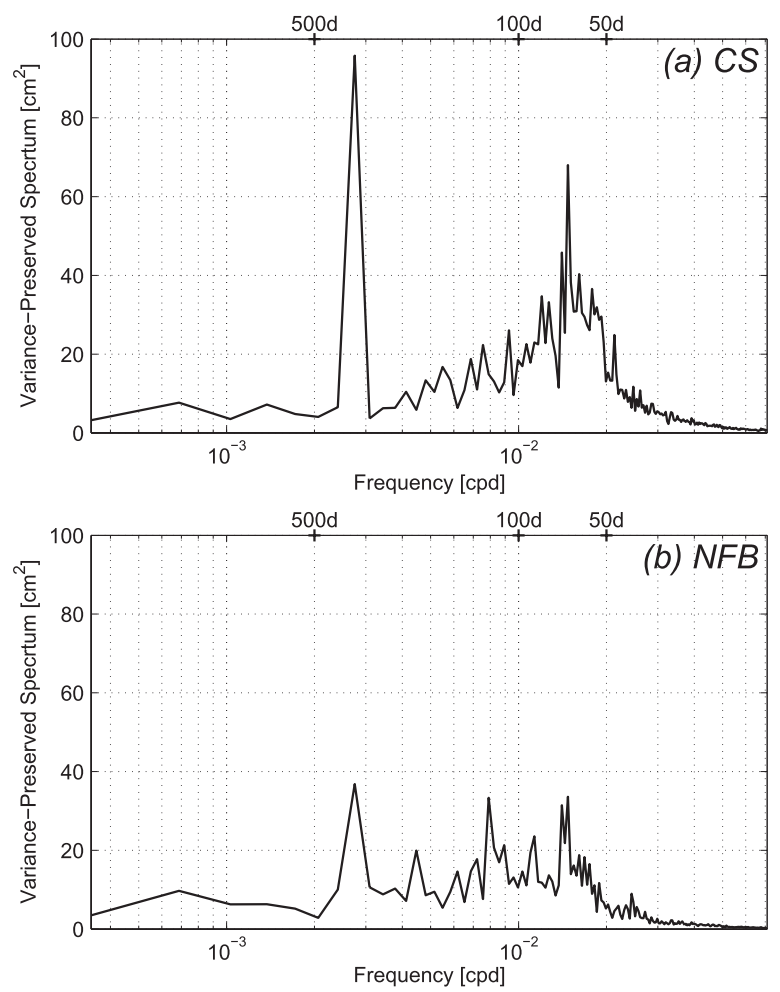

FIG. 5. Power spectra of SSH anomalies in (a) the Coral Sea at $14^{\circ}-18^{\circ} \mathrm{S}, 150^{\circ}-163^{\circ} \mathrm{E}$ and (b) the North Fiji Basin at $15^{\circ}-19^{\circ} \mathrm{S}$, $169^{\circ}-175^{\circ} \mathrm{E}$. The power spectra are plotted in variance preserving format.

A spectral analysis of the 14-yr-long SSH anomaly time series quantifies the dominant time scale of the observed SSH anomalies. Figures 5a,b show these power spectra averaged in the Coral Sea $\left(14^{\circ}-18^{\circ} \mathrm{S}\right.$, $\left.150^{\circ}-163^{\circ} \mathrm{E}\right)$ and the North Fiji Basin $\left(15^{\circ}-19^{\circ} \mathrm{S}, 169^{\circ}-\right.$ $175^{\circ} \mathrm{E}$ ), respectively. As may be inferred from Fig. 4 , the mesoscale spectral peak inside the Coral Sea is welldefined and has a predominant wave period close to 70 days (the exact spectral peak is at 67 days). With the phase speed estimated at $0.12 \mathrm{~m} \mathrm{~s}^{-1}$, this implies that the dominant wavelength of these 70-day eddy signals is around $700 \mathrm{~km}$. For comparison, the first baroclinic Rossby radius of deformation in the region is $\sim 70 \mathrm{~km}$ (Chelton et al. 1998, their Fig. 6). While less prominent, Fig. 5b reveals that the 70-day peak is also detectable in the SSH spectrum of the North Fiji Basin. In the North Fiji Basin, a spectral peak also appears around 125 days, which is absent in the neighboring Coral Sea. A clear spectral peak at the annual frequency is also seen in Figs. 5a,b. These have been attributed to the seasonal wind forcing in the region by Holbrook and Bindoff (1999), Chen and Qiu (2004), and Kessler and Gourdeau (2007) using baroclinic Rossby wave models, and they will not be pursued in this study.
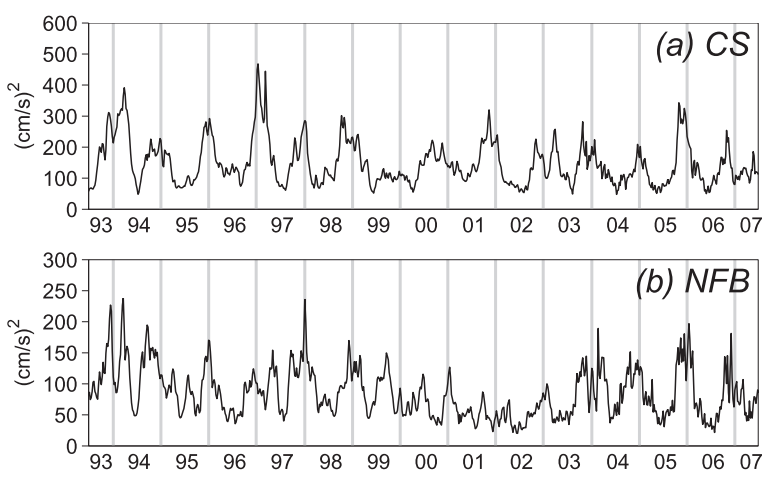

FIG. 6. Time series of EKE averaged in (a) the Coral Sea at $14^{\circ}-$ $18^{\circ} \mathrm{S}, 150^{\circ}-163^{\circ} \mathrm{E}$ and (b) the North Fiji Basin at $15^{\circ}-19^{\circ} \mathrm{S}, 169^{\circ}-$ $175^{\circ} \mathrm{E}$. Notice that the $y$-axis scales are different between (a) and (b).

A closer look at Fig. 4 suggests an annual modulation of the 70-day eddy signal. This can be quantified by plotting the eddy kinetic energy (EKE) time series in the Coral Sea and the North Fiji Basin (Fig. 6). Here, EKE is calculated from the high-pass-filtered SSH anomaly data, $h^{\prime}(x, y, t)$, by assuming geostrophy:

$$
\mathrm{EKE} \equiv \frac{g^{2}}{2 f^{2}}\left[\left(\frac{\partial h^{\prime}}{\partial x}\right)^{2}+\left(\frac{\partial h^{\prime}}{\partial y}\right)^{2}\right]
$$

where $g$ is the gravitational constant and $f$ is the Coriolis parameter. Although noticeable interannual changes are present in the time series, seasonal modulations in the EKE field with a maximum in austral summer and minimum in austral winter can easily be identified in Fig. 6. Notice that the seasonal peak-to-peak change in the EKE level in the Coral Sea has an average magnitude of $200 \mathrm{~cm}^{2} \mathrm{~s}^{-2}$, which is similar to the mean EKE level in the region of interest (i.e., $14^{\circ}-18^{\circ} \mathrm{S}, 150^{\circ}-$ $\left.163^{\circ} \mathrm{E}\right)$. Compared to the Coral Sea, the seasonal EKE modulation appears less regular in the North Fiji Basin; nevertheless, the seasonal peak-to-peak change in EKE, $\sim 100 \mathrm{~cm}^{2} \mathrm{~s}^{-2}$, is again as large as the regional mean EKE level.

With the 70-day eddy signals and their seasonal modulations better defined in the Coral Sea than in the North Fiji Basin, we will focus our analysis of their origin on the Coral Sea only.

\section{Forcing mechanism of the 70-day eddy variability}

It is worth emphasizing that because the NCJ-CSCCNVJ system in the Coral Sea is both horizontally and vertically sheared (Fig. 3), it possesses both the mean kinetic and the available potential energy necessary for barotropic and baroclinic instability, respectively. To 
clarify the relative importance of these two energy sources for the observed eddy variability, we start our examination in this section by adopting a $2 \frac{1}{2}$-layer reduced-gravity model as our theoretical framework.

\section{a. 21/2-layer reduced-gravity model}

The $2 \frac{1}{2}$-layer reduced-gravity model assumes that the ocean consists of two active upper layers and an inert, infinitely deep abyssal layer. Though simple in its formulation, the model is able to represent the essential aspects of both the horizontal and the vertical shear of the NCJ-CSCC-NVJ system in the Coral Sea. Based on the CARS climatology (Fig. 3a), we assume that the mean zonal flow in the two active layers $(n=1$ and 2$)$ has the following idealized pattern:

$$
\begin{aligned}
U_{n}(y)= & -U_{w n} \exp \left[-\left(y-y_{w}\right)^{2} / L_{w}^{2}\right] \\
& +U_{e n} \exp \left[-\left(y-y_{e}\right)^{2} / L_{e}^{2}\right],
\end{aligned}
$$

where the first term describes the westward-flowing South Equatorial Current as a Gaussian with a magnitude of $U_{w n}$, an $e$-folding width of $L_{w}$, and a central latitude at $y_{w}$. The second term in Eq. (2) describes the eastward-flowing CSCC in the surface layer and a split SEC in the second layer due to the blocking of Vanuatu. Parameters appropriate to the observed NCJ-CSCCNVJ system in the Coral Sea depend on the seasons. In August/September when the NCJ and CSCC are strongest, for example, $U_{w 1}=0.16 \mathrm{~m} \mathrm{~s}^{-1}, U_{w 2}=0.08 \mathrm{~m} \mathrm{~s}^{-1}$, $L_{w}=400 \mathrm{~km}, y_{w}=15.0^{\circ} \mathrm{S}, U_{e 1}=0.23 \mathrm{~m} \mathrm{~s}^{-1}, U_{e 2}=0.08$ $\mathrm{m} \mathrm{s}^{-1}, L_{e}=130 \mathrm{~km}$, and $y_{e}=15.5^{\circ} \mathrm{S}$, respectively; see Fig. 7a for the resultant $U_{n}(y)$ profiles. (Seasonal changes in the NCJ-CSCC-NVJ flow patterns are discussed in section $4 \mathrm{~b}$.)

Notice that $y_{w}$ is intentionally chosen different from $y_{e}$, so that the resulting $\mathrm{NVJ}$ speed is $\sim 50 \%$ larger than that of the NCJ as indicated in the observations. Also notice that the vertical shear associated with the CSCC is greater than that associated with the NVJ and NCJ, respectively.

Once the background mean flow pattern is specified, the linearized equations governing the perturbation potential vorticity $q_{n}$ in the two active layers $(n=1$ and 2$)$ become

$$
\left(\frac{\partial}{\partial t}+U_{n} \frac{\partial}{\partial x}\right) q_{n}+\frac{\partial \Pi_{n}}{\partial y} \frac{\partial \phi_{n}}{\partial x}=0
$$

where $\phi_{n}$ is the perturbation streamfunction and $\Pi_{n}$ is the mean potential vorticity of the $n$th layer (Pedlosky 1987, chapter 7). Given $U_{n}$ (y) in Eq. (2), $q_{n}$ and the
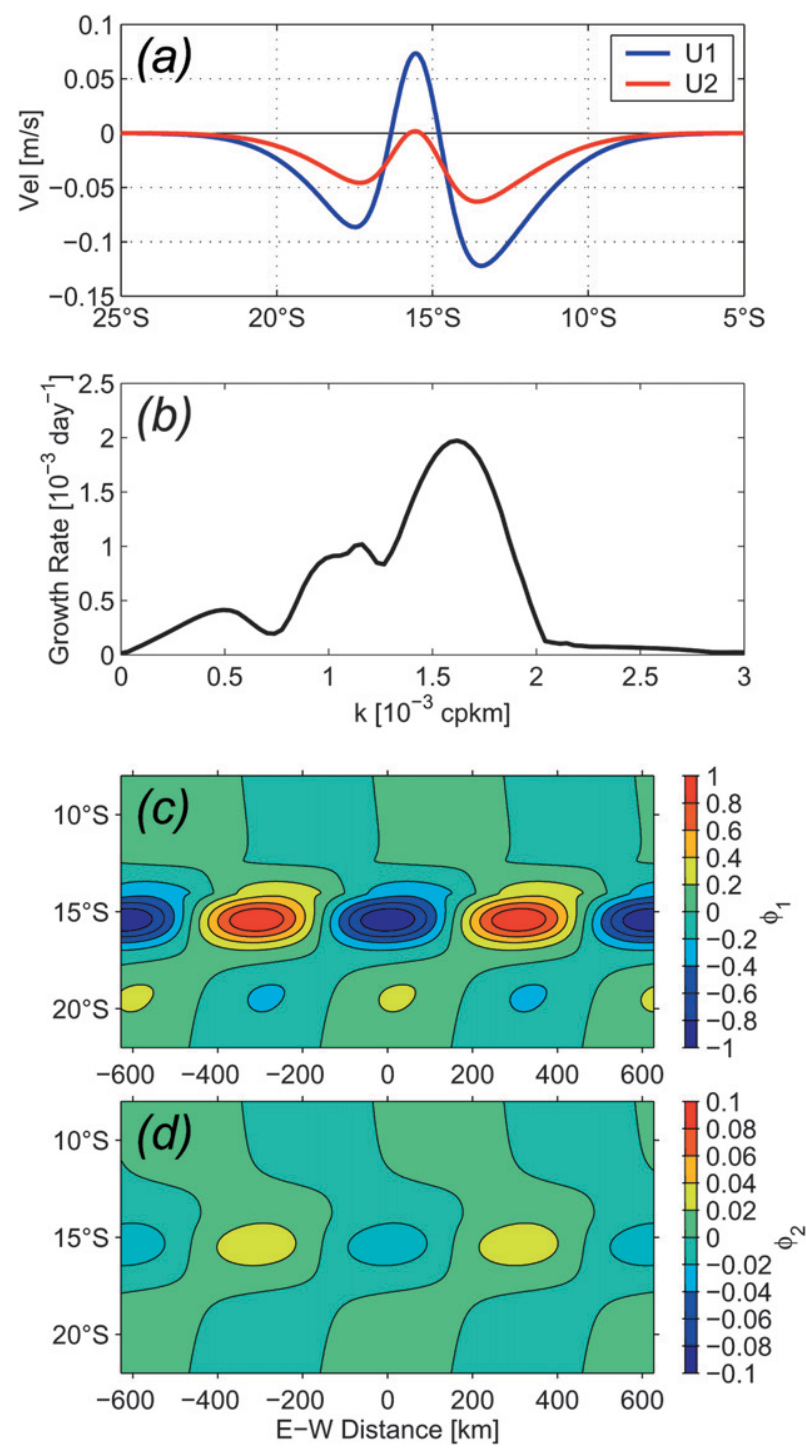

FIG. 7. (a) First- and second-layer zonal-mean velocity patterns assumed for the $2 \frac{1}{2} 2$-layer NCJ-CSCC--NVJ system in August/ September; see Eq. (2). (b) Growth rate as a function of zonal wavenumber $k$. (c) First-layer perturbation streamfunction pattern for the most unstable wave: $k_{\max }=1.6 \times 10^{-3} \mathrm{cpkm}$. Amplitudes of the pattern are normalized. (d) Same as in (c), except for the second-layer perturbation streamfunction pattern.

meridional gradient of $\Pi_{n}$ are related to the other variables of the model as follows:

$$
q_{n}=\nabla^{2} \phi_{n}+\frac{(-1)^{n}}{\lambda_{n}^{2}}\left[\phi_{1}-\phi_{2}-(n-1) \gamma \phi_{2}\right]
$$

$$
\frac{\partial \Pi_{n}}{\partial y}=\beta-\frac{d^{2} U_{n}(y)}{d y^{2}}-\frac{(-1)^{n}}{\lambda_{n}^{2}}\left[U_{1}-U_{2}-(n-1) \gamma U_{2}\right],
$$


where

$$
\begin{aligned}
\gamma= & g_{12}^{\prime} / g_{23}^{\prime}, \quad g_{n m}^{\prime}=\left(\rho_{m}-\rho_{n}\right) g / \rho_{o}, \quad \text { and } \\
& \lambda_{n}^{2}=g_{12}^{\prime} H_{n} / f^{2} .
\end{aligned}
$$

In the above equations, $\nabla^{2}$ denotes the horizontal Laplacian operator, $\rho_{n}$ is the $n$th layer density (here we choose $\rho_{1}=24.8, \rho_{2}=26.6$, and $\left.\rho_{1}=27.75 \sigma_{\theta}\right), \beta$ is the meridional gradient of the Coriolis parameter $f$, and $\rho_{o}$ is the reference density. In Eq. (6), $H_{n}(y)$ is the mean $n$th layer thickness, which is related to $U_{n}(y)$ through geostrophy: $f U_{n}=-\partial\left(g_{n 3}^{\prime} H_{1}+g_{23}^{\prime} H_{2}\right) / \partial y$. In the following calculation, we assume that the unperturbed surface and subsurface layers have a mean thickness of 200 and $600 \mathrm{~m}$, respectively.

The stability of the above-specified NCJ-CSCC-NVJ system can be analyzed by seeking the normal mode solutions: $\phi_{n}=\operatorname{Re}\left[A_{n}(y) \operatorname{expi}(k x-k c t)\right]$. By substituting $\phi_{n}$ into Eq. (3), we can solve for $A_{n}$ numerically by regarding the complex phase speed $c=c_{r}+i c_{i}$ as an eigenvalue. Figure $7 \mathrm{~b}$ shows the growth rate $k c_{i}$ as a function of the zonal wavenumber $k$. The most unstable mode is obtained when $k_{\max }=1.6 \times 10^{-3} \mathrm{cpkm}$, or when the perturbation wavelength is $625 \mathrm{~km}$. This wavelength of the maximum growth rate agrees well with the dominant wavelength of the 70-day eddy signals observed in the Coral Sea (recall section 3).

Figures $7 \mathrm{c}, \mathrm{d}$ show the spatial structures of $\phi_{n}(x, y)$ for the most unstable mode. The perturbations are concentrated along the CSCC axis centered on $15.5^{\circ} \mathrm{S}$. Despite the presence of vertical shear, the anomalies are coherent in the vertical, implying that it is the horizontal shear of the NCJ-CSCC-NVJ system that is responsible for the excitation of the most unstable mode. The NCJ-CSCC-NVJ system is less prone to baroclinic instability, despite the presence of significant vertical shear, because of its low latitude. Compared with the STCC bands along $\sim 25^{\circ} \mathrm{S}$, where the enhanced eddy variability is known to result from baroclinic instability (e.g., Qiu 1999; Roemmich and Gilson 2001; Kobashi and Kawamura 2002), the phase speeds of the free baroclinic Rossby waves in the Coral Sea are faster, making it more difficult for the mean-flow-modified Rossby modes to interact with and release the available potential energy. [Readers interested in the proof of this statement are referred to Qiu and Chen (2004, section 3).]

\section{b. 11/2-layer reduced-gravity model}

To confirm that barotropic instability associated with the horizontal shear of the NCJ-CSCC-NVJ system is the primary cause for the observed eddy variability, as well as to explore further the dependence of instability on relevant physical parameters, in this subsection we adopt a $1 \frac{1}{2}$-layer reduced-gravity model that excludes the possibility of baroclinic instability. In this model, the linearized equation governing the active upper-layer perturbation potential vorticity $q$ is

$$
\left(\frac{\partial}{\partial t}+U \frac{\partial}{\partial x}\right) q+v \frac{\partial \Pi}{\partial y}=0
$$

where

$$
\Pi=\frac{f-U_{y}}{H} \quad \text { and } \quad q=\frac{1}{H}\left(\frac{\partial v}{\partial x}-\frac{\partial u}{\partial y}\right)-\frac{h}{H} \Pi .
$$

In Eqs. (7) and (8), $\Pi$ is the mean potential vorticity, $H(y)$ is the mean upper-layer thickness, which is in geostrophic balance with the background surface layer $U(y)$ through $f U=-g^{\prime} H_{y}, g^{\prime}$ is the reduced gravity, $(u, v)$ are the perturbation upper-layer velocities, and $h$ is the perturbation upper-layer thickness. Using the quasigeostrophic approximation to relate u to $h$ (i.e., $\left.f \mathbf{k} \times \mathbf{u}=-g^{\prime} \nabla h\right)$ and assuming a normal mode solution $h=\operatorname{Re}[A(y) \exp i(k x-k c t)]$, we can again solve for $A(y)$ numerically by regarding the complex phase speed $c$ as an eigenvalue. Aside from $U(y)$, the only external physical parameter that needs to be specified in the present 11/2-layer reduced-gravity model is the baroclinic Rossby radius $\lambda=g^{\prime} H / f^{2}$. Following Chelton et al. (1998), we set $\lambda=70 \mathrm{~km}$.

Choosing $U(y)=U_{1}(y)$ used in the $2^{1 / 2}$-layer model, we plot in Fig. $8 \mathrm{~b}$ the growth rate $k c_{i}$ as a function of zonal wavenumber $k$ from the $1 \frac{1}{2} 2$-layer reduced-gravity model. Similar to that shown in Fig. 7b, the most unstable wave has a zonal wavenumber $k_{\max }=1.53 \times 10^{-3}$ cpkm, or a wavelength of $650 \mathrm{~km}$; its corresponding upper-layer thickness anomaly has a spatial pattern (Fig. 8c) very much resembling that of the $2^{1} \frac{1}{2}$-layer model (cf. Figure 7c). These results confirm that it is the horizontal shear in the NCJ-CSCC-NVJ system that is responsible for the unstable waves observed along the CSCC band and that adding the effect of vertical shear does not significantly alter the characteristics of the system's most unstable mode.

The $U(y)$ pattern specified in Fig. 8a represents the mean flow condition of the NCJ-CSCC-NVJ system in August/September when the NCJ and CSCC are strongest (Fig. 9). As the season progresses, the NCJ and CSCC wane while the NVJ grows to their north. This phase lag between the two westward jets is due to annual Rossby waves driven by the basin-scale winds, which propagate faster at $13^{\circ} \mathrm{S}$ than at $18^{\circ} \mathrm{S}$ (e.g., Kessler and Gourdeau 2007). The strength of the CSCC, by contrast, is due to the seasonal modulation of the 

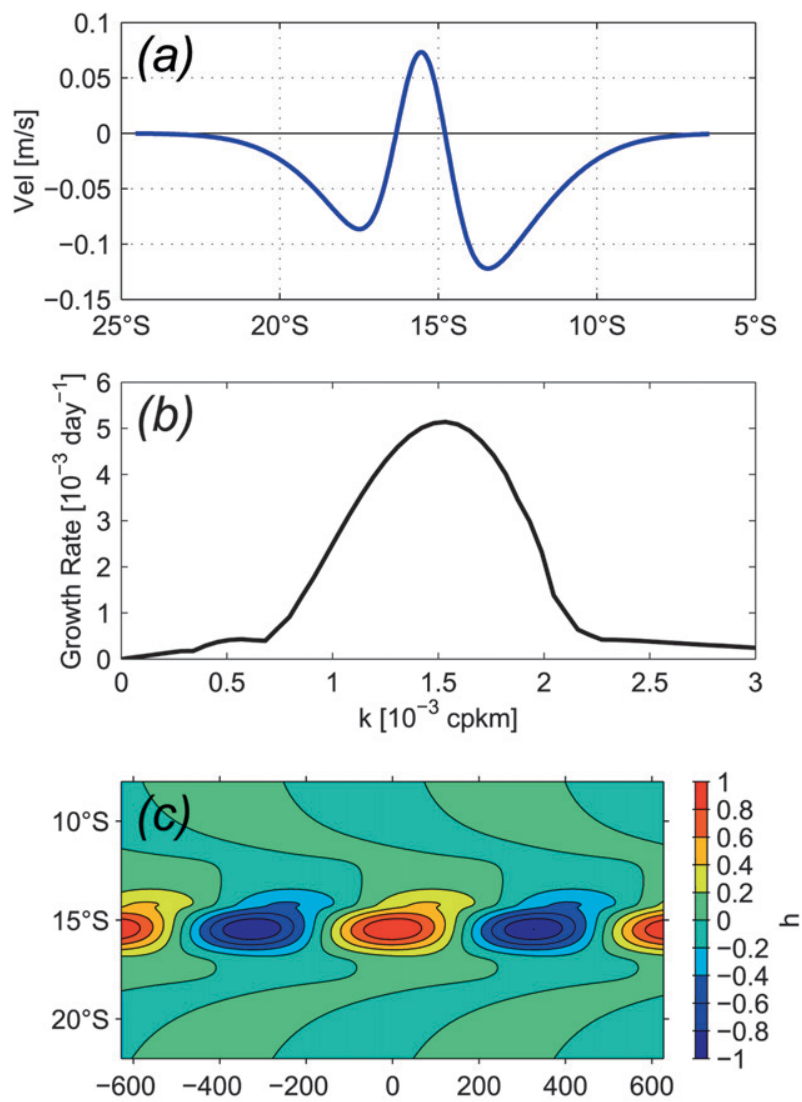

FIG. 8. (a) Upper-layer zonal-mean velocity pattern assumed for the 1ㄹ-layer NCJ-CSCC-NVJ system in August/September; same as $U_{1}(y)$ in Fig. 7a. (b) Growth rate as a function of zonal wavenumber $k$. (c) Upper-layer thickness anomaly pattern for the most unstable wave: $k_{\max }=1.53 \times 10^{-3} \mathrm{cpkm}$. Amplitudes of the pattern are normalized.

local wind stress curl in the lee of Vanuatu, which is strongest in July to September when the trade winds are in their northernmost position and the curl dipole is most intense.

To examine the impact of the seasonal background mean flow changes on the NCJ-CSCC-NVJ system, we approximate the observed flow pattern shown in Fig. 9 by $U(y)=-U_{w} \exp \left[-\left(y-y_{w}\right)^{2} / L_{w}^{2}\right]+U_{e} \exp \left[-\left(y-y_{e}\right)^{2} /\right.$ $L_{e}^{2}$ ] [recall Eq. (2)] on a bimonthly basis. Table 1 lists the appropriate parameter values, and the resultant bimonthly $U(y)$ patterns are displayed in Figs. 10a,c. For each of the bimonthly $U(y)$ patterns, a stability analysis was done; the corresponding growth rates as a function of zonal wavenumber $k$ are shown in Figs. 10b,d. Reflecting the modulation in the horizontal shear in the mean flow system, the growth rate of the most unstable waves exhibits a well-defined annual cycle: the maximum growth occurs in December/January when the CSCC-NVJ shear is maximum, and the minimum

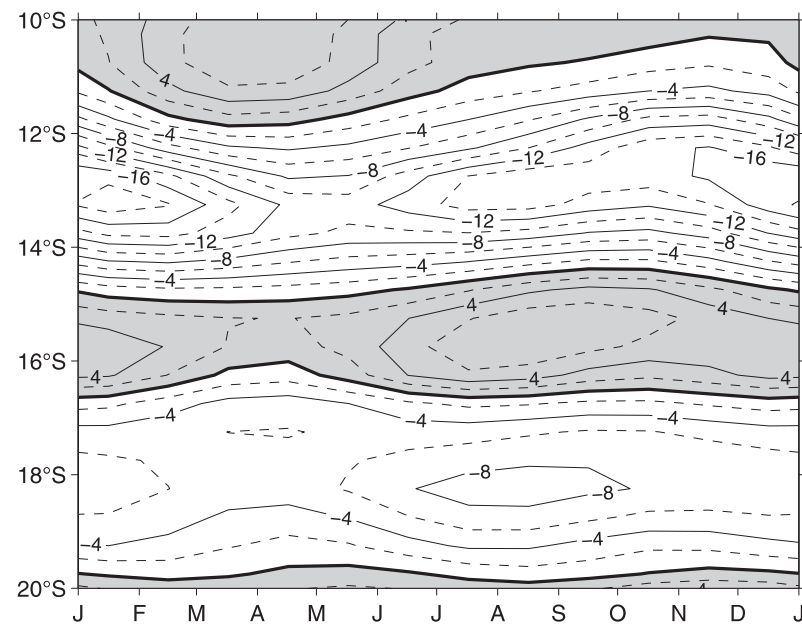

FIG. 9. Geostrophic zonal flow $\left(\mathrm{cm} \mathrm{s}^{-1}\right)$ averaged from $160^{\circ}$ to $165^{\circ} \mathrm{E}$ and in the upper 200-m layer in the Coral Sea. Based on the CARS climatological $T-S$ data with the reference level at 1100 dbar. Eastward flows are gray shaded.

growth takes place in April/May when the three jets become the weakest.

Notice that the maximum growth rate under the December/January condition is more than 5 times greater than that under the April/May condition. This difference in the strength of barotropic instability associated with the seasonally modulating NCJ-CSCCNVJ shear likely explains the seasonal eddy kinetic energy modulation captured in the satellite altimeter data (Fig. 6a). While the maximum growth rates depend sensitively on seasons, the characteristics of the corresponding most unstable modes are, on the other hand, less sensitive to seasons: the most unstable mode in all seasons (not shown) has a spatial pattern similar to that presented in Fig. 8c, and the wavelength of the most unstable waves differs only by $17 \%$, ranging from 650 to $770 \mathrm{~km}$. This wavelength value matches well to the wavelengths of the $\sim 700-\mathrm{km}, 70$-day eddy signals detected along the CSCC band in the Coral Sea.

TABLE 1. Bimonthly parameter values appropriate for the NCJ-CSCC-NVJ zonal-mean flow system in the Coral Sea The zonal-mean flow is assumed to have the pattern $U(y)=$ $-U_{w} \exp \left[-\left(y-y_{w}\right)^{2} / L_{w}^{2}\right]+U_{e} \exp \left[-\left(y-y_{e}\right)^{2} / L_{e}^{2}\right]$. Common seasonally independent parameter values are $L_{w}=400 \mathrm{~km}, L_{e}=130$ $\mathrm{km}$, and $y_{e}=15.5^{\circ} \mathrm{S}$.

\begin{tabular}{lccc}
\hline \hline \multicolumn{1}{c}{ Months } & $U_{w}\left(\mathrm{~m} \mathrm{~s}^{-1}\right)$ & $y_{w}\left({ }^{\circ} \mathrm{S}\right)$ & $U_{e}\left(\mathrm{~m} \mathrm{~s}^{-1}\right)$ \\
\hline August/September & 0.16 & 15.0 & 0.23 \\
October/November & 0.17 & 14.5 & 0.21 \\
December/January & 0.18 & 14.0 & 0.19 \\
February/March & 0.15 & 14.0 & 0.16 \\
April/May & 0.12 & 14.5 & 0.13 \\
June/July & 0.14 & 14.7 & 0.18 \\
\hline
\end{tabular}



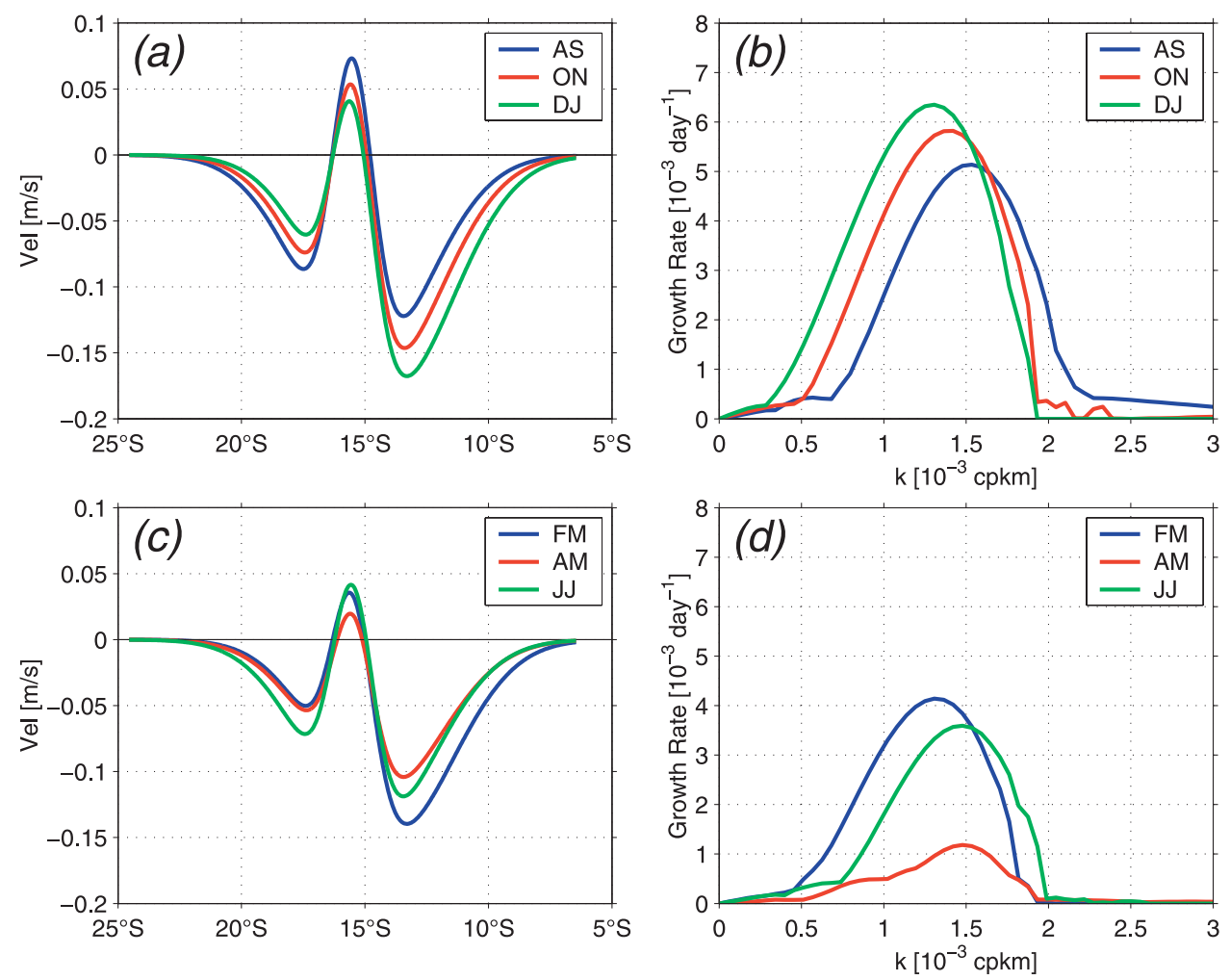

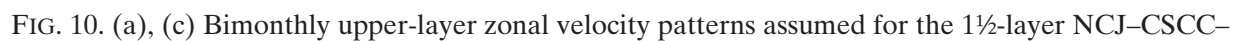
NVJ system; see Table 1 for parameter values. (b), (d) Corresponding growth rates as a function of zonal wavenumber $k$.

In concluding this subsection, we emphasize that the observed SSH anomaly data support the notion that the enhanced eddy variability along the CSCC band is due to barotropic instability of the horizontally sheared NCJ-CSCC-NVJ system. To quantify this, Fig. 11 shows the Reynolds stress $\overline{u^{\prime} v^{\prime}}$ values averaged zonally from $152.5^{\circ}$ to $162.5^{\circ} \mathrm{E}$ as a function of latitude. Notice that $\overline{u^{\prime} v^{\prime}}$ is positive north and negative south of $15.5^{\circ} \mathrm{S}$, the center of the CSCC. As indicated in Fig. 9, north of $15.5^{\circ} \mathrm{S}$, mean $\partial U / \partial y$ between the CSCC and NVJ is negative, while south of $15.5^{\circ} \mathrm{S}, \partial U / \partial y$ between the CSCC and NCJ is positive. That the observed Reynolds stresses are aligned against the zonal-mean flow shear implies that the eddies extract energy from the lateral shear of the background NCJ-CSCC-NVJ system; this is consistent with the barotropic instability mechanism based on the stability analyses of this section.

\section{Summary and discussion}

A region of enhanced mesoscale eddy variability centered along $\sim 16^{\circ} \mathrm{S}$ in the Coral Sea is detected from altimeter-derived sea surface height data during the past
14 years. The eddy signals have a dominant wave period of $\sim 70$ days and a wavelength of $\sim 700 \mathrm{~km}$, and they propagate westward at a speed of $\sim 0.12 \mathrm{~cm}^{-1}$. Similar mesoscale eddy signals with a lesser amplitude are also detected in the neighboring North Fiji Basin along $\sim 18^{\circ} \mathrm{S}$. In both basins, the amplitudes of the mesoscale eddy signals have a well-defined annual cycle with a maximum in December/January and a minimum in May/June, and the peak-to-peak seasonal changes in eddy kinetic energy (EKE) level are as large as the background regional-mean EKE level.

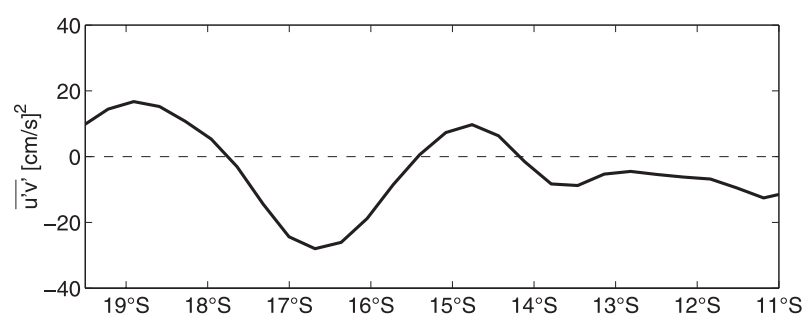

FIG. 11. Reynolds stress $\overline{u^{\prime} v^{\prime}}$ values averaged zonally from $152.5^{\circ}$ to $162.5^{\circ} \mathrm{E}$ as a function of latitude. Here, $u^{\prime}$ and $v^{\prime}$ are calculated from the high-pass-filtered SSH anomaly data and overbar denotes the time average over the past $14 \mathrm{yr}$. 


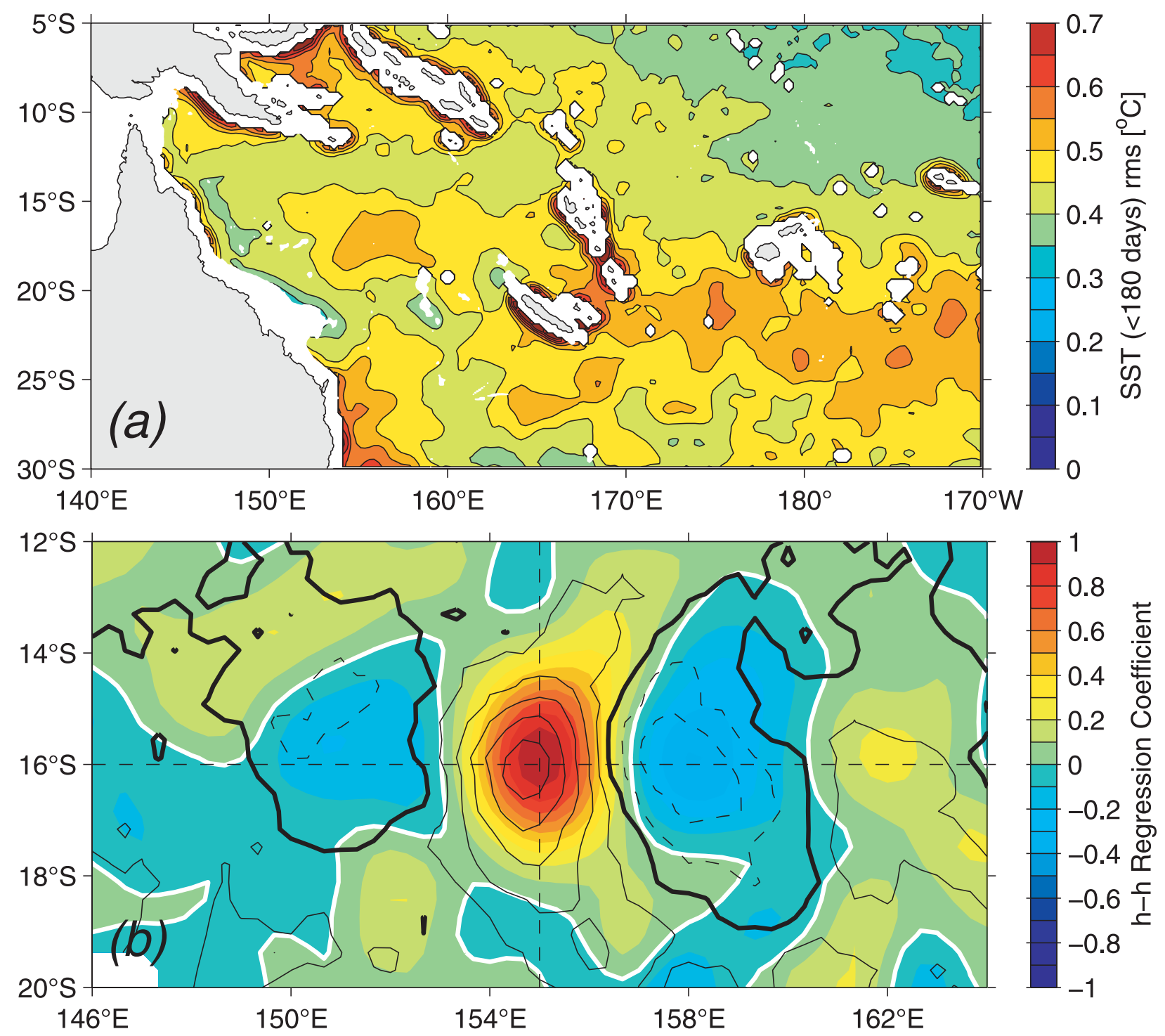

FIG. 12. (a) Rms amplitude of the high-pass-filtered SST field. The high-pass filter has a half-power at 180 days. Based on the weekly TMI SST data from December 1997 to June 2007. (b) Linear regressions of SSH and SST anomalies onto the SSH anomaly time series at $16^{\circ} \mathrm{S}$ and $155^{\circ} \mathrm{E}$. The SSH regression is shown in colored shades and the SST regression in contours.

The high EKE band along $16^{\circ} \mathrm{S}$ in the Coral Sea corresponds to the path of the Coral Sea Countercurrent (CSCC). Similarly, the high EKE band along $18^{\circ} \mathrm{S}$ in the North Fiji Basin occurs along the axis of the Fiji Basin Countercurrent (FBCC). Both of these countercurrents flow eastward, and they are generated by localized, dipolar wind stress curl forcing in the lee of the Vanuatu and Fiji islands, respectively. Occurring between the westward-flowing jets resulting from the bifurcated South Equatorial Current (in the Coral Sea case, these jets correspond to the North Caledonian jet and the North Vanuatu jet), the presence of the windinduced countercurrents acts to enhance the horizontal shear of the mean flows west of the Vanuatu and Fiji islands. In this study, we hypothesize that the elevated mesoscale eddy variability detected in the Coral Sea and the North Fiji Basin is due to barotropic instability of these laterally sheared, background zonal jets.

To test this hypothesis, background NCJ-CSCC-NVJ flow patterns were estimated from available observations and shown to be consistent with the Sverdrup circulation based on mean scatterometer wind stresses and the Godfrey (1989) Island Rule. Comparing the stability analysis results from a $2 \frac{1}{2}-$-layer versus a $1 \frac{1}{2}-$ layer reduced-gravity model, we found that the most unstable mode in the system has an equivalent 


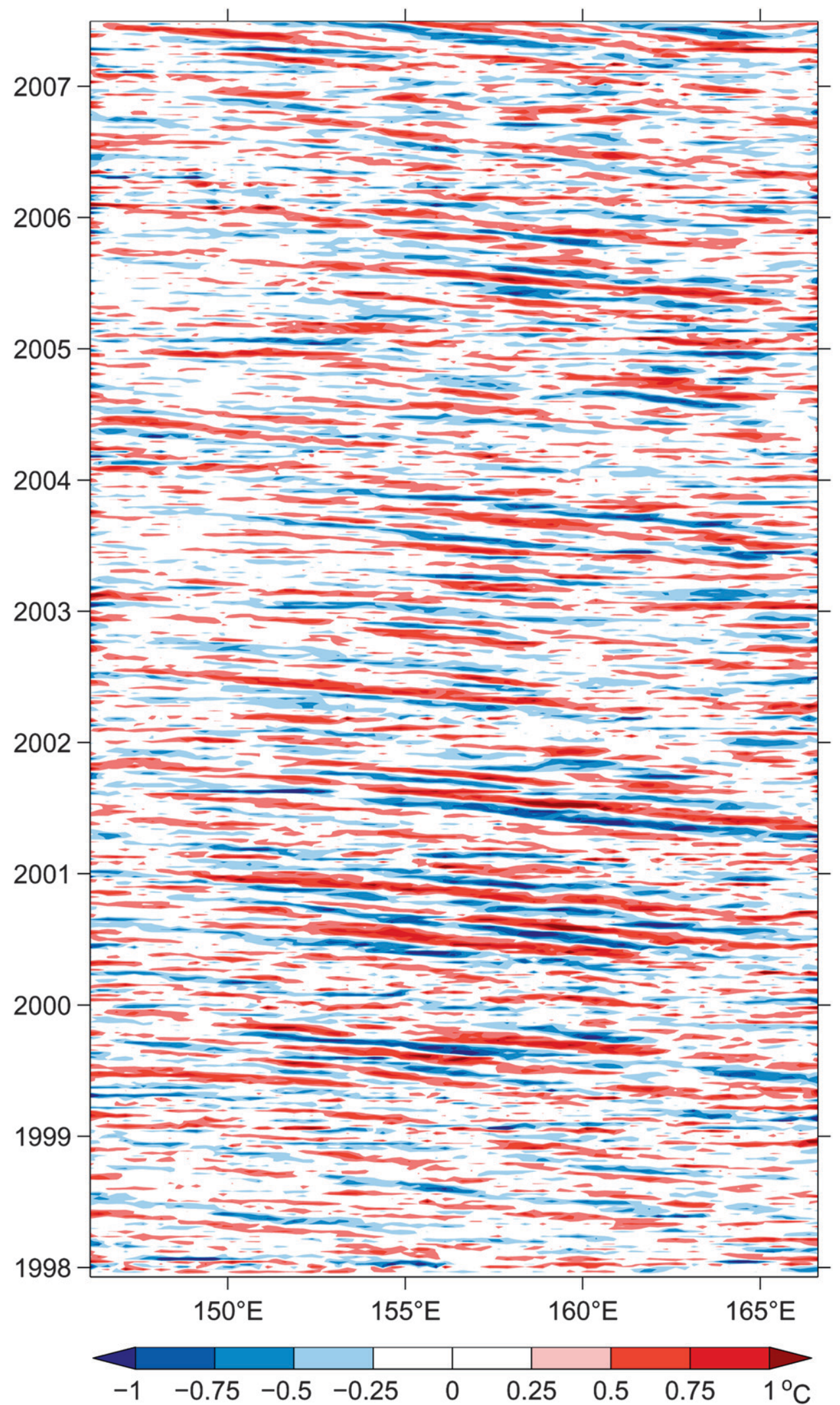

FIG. 13. Time-longitude plot of high-pass-filtered SST anomalies along $16^{\circ} \mathrm{S}$ in the Coral Sea. The highpass filter has a half-power at 180 days and the zonally coherent SST signals have been removed. Based on the weekly, $0.5^{\circ} \times 0.5^{\circ}$, TMI SST data. 
barotropic structure in the vertical; further, that exclusion of the lower layer in the 11/2-layer model produces essentially the same surface ocean perturbation pattern as that in the $2 \frac{1}{2}-$-layer model. The model-predicted, most unstable upper ocean anomalies have a zonal wavelength of $650-770 \mathrm{~km}$, which matches well with that detected in the satellite altimeter data. Given that the fully developed SSH anomalies propagate westward at the speed of baroclinic Rossby waves, the correct prediction for the zonal wavelength of the SSH anomalies implies a comparable prediction for the observed 70-day wave period as well.

That barotropic instability is the main cause for the enhanced eddy variability along the CSCC is supported by the observed SSH anomaly data; specifically, the Reynolds stresses inferred from the SSH anomaly data are tilted against the meridional shear of the background NCJ-CSCC-NVJ flow. On the seasonal time scale, the intensity of the NCJ-CSCC-NVJ horizontal shear reaches a maximum (minimum) in the austral summer (winter) months. This seasonal change in the lateral shear of the NCJ-CSCC-NVJ system modulates the growth rate of barotropic instability and accounts for the December/January maximum and May/June minimum of the EKE level observed in the Coral Sea.

The westward-flowing NCJ and NVJ bifurcate at the coast of Australia. With the northern branch of this flow eventually feeding the equatorial Pacific Ocean via the western boundary, the enhanced mesoscale eddy variability in the Coral Sea can modify the properties of water masses originating in the midlatitude South Pacific and potentially influence the upper ocean temerature-salinity $(T-S)$ characteristics important for the air-sea interaction in the equatorial band (e.g., Kessler 1999; Maes et al. 2007). While a full investigation into the eddy-induced water mass modifications in the Coral Sea is beyond the scope of this study, it is useful to briefly discuss the sea surface temperature variability in the Coral Sea in connection to the NCJ-CSCC-NVJ's instability. Figure 12a shows the rms amplitude of highpass-filtered SST anomalies in the southwest Pacific Ocean. Here, the SST data is based on the Tropical Rainfall Measuring Mission (TRMM) Microwave Imager (TMI) measurements from December 1997 to June 2007 (Wentz et al. 2000). The spatial pattern of the mesoscale SST variability bears a close resemblance to that of Fig. 1b derived from the high-pass-filtered SSH data. In the Coral Sea, enhanced SST variability with an rms amplitude exceeding $0.5^{\circ} \mathrm{C}$, for example, appears along the path of NCJ-CSCC-NVJ. Plotting the SST anomalies along $16^{\circ} \mathrm{S}$ as a function of time and longitude (Fig. 13) reveals that all of the mesoscale eddy characteristics captured by the satellite altimeter data, such as the 70-day wave period and the $0.12 \mathrm{~m} \mathrm{~s}^{-1}$ westwardpropagation speed, are detectable in the SST data. The SST anomalies have a typical peak-to-peak amplitude of $\pm 1^{\circ} \mathrm{C}$.

To clarify the phase relationship between the SSH and SST anomalies, we regress the SSH and SST anomaly data in the Coral Sea onto the SSH anomaly time series at a fixed point: $16^{\circ} \mathrm{S} .155^{\circ} \mathrm{E}$. As presented in Fig. 12b, a positive (negative) SSH anomaly corresponds very well to a warm (cold) SST anomaly; the spatial phase difference between these two anomaly fields is $\sim 50 \mathrm{~km}$, which is much smaller than the horizontal size of the anomalies. This in-phase relationship between the SST and SSH anomalies implies the equivalent barotropic structure of the eddy signals. The fact that the cophase lines of the SSH and SST anomalies in Fig. 12b tilt against the mean shear of the background NCJ-CSCC-NVJ flow system reflects again a consequence of barotropic instability (recall Fig. 8c).

The results of Figs. 12, 13 indicate that barotropic instability of the NCJ-CSCC-NVJ system likely contributes to the meridional heat exchange of the upper ocean across the Coral Sea. At present, we do not have the needed observational data to quantify the effect of this eddy-induced heat exchange on the upper ocean heat budget in the region. An international observational program, the Southwest Pacific Ocean Circulation and Climate Experiment (SPICE), is currently being implemented in the region surrounding the Coral Sea (Ganachaud et al. 2007). It will be interesting for future studies to clarify both how the enhanced eddy variability influences the regional heat budget and water mass transformations, and the extent to which these regional changes affect the areas "downstream" of the Coral Sea.

Acknowledgments. This study benefited from discussions with Alex Ganachaud and Justin Small. Lionel Gourdeau and an anonymous reviewer pointed us to the importance of the CSCC. We thank Russ Davis and Lionel Gourdeau, co-PIs with WSK, for agreeing to our use of the spray glider data. The TMI SST data were provided by Remote Sensing Systems, and the merged satellite altimeter data by the CLS Space Oceanography Division as part of the Environment and Climate EU ENACT project. This study was supported by NASA through Contract 1207881.

\section{APPENDIX}

\section{Island Rule Applied to the Southwest Pacific Ocean}

The Godfrey (1989) Island Rule determines the total meridional transport between an island and the coast to 
its east (thus including the western boundary transport along the island's coast), using the interior wind-driven Sverdrup flow plus the assumption of cross-stream geostrophy in western boundary currents (see also Wajsowicz 1993; Pedlosky et al. 1997). The original island rule was formulated in terms of the pressure difference between the northern and southern tips of the island, but a perhaps more physically intuitive derivation shows that the transport between the island and the coast to its east, $T_{0}$, is the interior Sverdrup transport $T_{\mathrm{S} v}=\int \operatorname{curl} \tau d x / \beta$, averaged over the latitude range of the island, plus a term depending on the wind circulation around the island,

$$
T_{0}=\overline{T_{\mathrm{Sv}}}+\frac{1}{f_{N}-f_{S}} \oint_{\text {Island }} \tau^{l} d l
$$

where the overbar indicates a meridional average; $f_{N}$ and $f_{S}$ are the Coriolis parameter at the north and south tips of the island, respectively; $\tau$ is the wind stress divided by the density of seawater; and the path $l$ circulates counterclockwise around the island's coast (Godfrey 1989; Wajsowicz 1993). Equation (A1) says that if the circumisland wind circulation is small, as is usually the case for small islands, then the total transport $T_{0}$ equals the average Sverdrup transport, in which case there will be no net (meridional average) western boundary current transport against the island.

The island rule transport shown in Fig. 2c was calculated from the mean ERS winds and curl (Figs. 2a,b), working west from South America where $T_{0}$ was taken to be zero, with the island circulation term estimated for Fiji, Vanuatu, New Caledonia, the Solomon Islands, New Zealand, and Australia-New Guinea. As expected, this term is small (less than $0.2 \mathrm{~Sv}$ ) for the first three islands but is about $-1.3 \mathrm{~Sv}$ (clockwise) for the Solomon Islands, and nearly $+1 \mathrm{~Sv}$ for Australia-New Guinea and New Zealand. It should be noted that these estimates are subject to a large uncertainty, because defining the "coastal" wind depends on the match between the resolution of the wind data and the scale over which the coastal wind is felt by the ocean; in addition, defining the effective size of island groups is ambiguous. Only in the case of the Solomon Islands is the island term a major feature of the deduced circulation, where it produces a net southward western boundary current along the east coast of the islands and corresponding northward transport of the New Guinea Coastal Current in the Solomon Sea. Once the island terms were estimated, a complete solution was found by applying (A1), iteratively in the case of meridionally overlapping islands, to determine the transport $T_{0}$, relative to South America, for each island. Differences between the various values of $T_{0}$ give the total transports between pairs of islands.
The interior solution is the usual Sverdrup transport, with the integration carried up to one grid point east of each coast and the value of the complete streamfunction $\psi$ at the island set to $-T_{0}$ around its entire coast. (Because the meridional transport is $\psi_{x}$, where $\psi=0$ at the coast of South America, the value of $\psi$ at the island is $-T_{0}$.) The interior Sverdrup integration is restarted at the west side of each island with the value $-T_{0}$.

The western boundary currents are the differences between $\psi$ at the coasts and the interior streamfunction just to their east (Fig. 2c). For the case of AustraliaNew Guinea, $T_{0}=11 \mathrm{~Sv}$ (which is the total transport between South America and Australia, and by inference the transport of the Indonesian Throughflow in this linear model), yielding a northward western boundary current of up to $25 \mathrm{~Sv}$ at $10^{\circ} \mathrm{S}$.

\section{REFERENCES}

Bowen, M. M., J. L. Wilkin, and W. J. Emery, 2005: Variability and forcing of the East Australian Current. J. Geophys. Res., 110, C03019, doi:10.1029/2004JC002533.

Chelton, D. B., and M. G. Schlax, 1996: Global observations of oceanic Rossby waves. Science, 272, 234-238.

, R. A. de Szoeke, M. G. Schlax, K. E. Naggar, and N. Siwertz, 1998: Geographical variability of the first baroclinic Rossby radius of deformation. J. Phys. Oceanogr., 28, 433-460.

,,-- M. H. Freilich, and R. F. Milliff, 2004: Satellite measurements reveal persistent small-scale features in ocean winds. Science, 303, 978-983.

Chen, S., and B. Qiu, 2004: Seasonal variability of the South Equatorial Countercurrent. J. Geophys. Res., 109, C08003, doi:10.1029/2003JC002243.

Chiswell, S. M., G. J. Rickard, and M. M. Bowen, 2007: Eulerian and Lagrangian eddy statistics of the Tasman Sea and southwest Pacific Ocean. J. Geophys. Res., 112, C10004, doi:10.1029/2007JC004110.

Davis, R. E., C. E. Eriksen, and C. P. Jones, 2002: Autonomous buoyancy-driven underwater gliders. The Technology and Application of Autonomous Underwater Vehicles, G. Griffiths, Ed., Taylor and Francis, 324 pp.

Ducet, N., P.-Y. Le Traon, and G. Reverdin, 2000: Global highresolution mapping of ocean circulation from TOPEX/Poseidon and ERS-1 and -2. J. Geophys. Res., 105, 19 477-19 498.

Ganachaud, A., and Coauthors, 2007: Southwest Pacific Ocean Circulation and Climate Experiment (SPICE)-Part I. Scientific background. CLIVAR Publication Series 111, NOAA OAR Special Rep., NOAA/OAR/PMEL, 37 pp.

Godfrey, J. S., 1989: A Sverdrup model of the depth-integrated flow for the world ocean allowing for island circulations. Geophys. Astrophys. Fluid Dyn., 45, 89-112.

Gourdeau, L., W. S. Kessler, R. E. Davis, J. Sherman, C. Maes, and E. Kestenare, 2008: Zonal jets entering the Coral Sea. J. Phys. Oceanogr., 38, 715-725.

Holbrook, N. J., and N. L. Bindoff, 1999: Seasonal temperature variability in the upper Southwest Pacific Ocean. J. Phys. Oceanogr., 29, 366-381.

Hughes, C. W., 2002: Zonal jets in and near the Coral Sea, seen by satellite altimetry. Geophys. Res. Lett., 29, 1330, doi:10.1029/ $2001 G L 014006$. 
Kessler, W. S., 1999: Interannual variability in the subsurface high-salinity tongue south of the equator at $165^{\circ} \mathrm{E}$. J. Phys. Oceanogr., 29, 2038-2049.

— Pacific Ocean. Geophys. Res. Lett., 33, L03608, doi:10.1029/ 2005GL025084.

—, and — 2007: The annual cycle of circulation of the southwest subtropical Pacific, analyzed in an ocean GCM. J. Phys. Oceanogr., 37, 1610-1627.

Kobashi, F., and H. Kawamura, 2002: Seasonal variation and instability nature of the North Pacific Subtropical Countercurrent and the Hawaiian Lee Countercurrent. J. Geophys. Res., 107, 3185, doi:10.1029/2001JC001225.

Le Traon, P.-Y., F. Nadal, and N. Ducet, 1998: An improved mapping method of multisatellite altimeter data. J. Atmos. Oceanic Technol., 25, 522-534.

Maes, C., L. Gourdeau, X. Couvelard, and A. Ganachaud, 2007: What are the origins of the Antarctic Intermediate Waters transported by the North Caledonian Jet? Geophys. Res. Lett., 34, L21608, doi:10.1029/2007GL031546.

Merle, J., H. Rotschi, and B. Voituriez, 1969: Zonal circulation in the tropical western South Pacific at $170^{\circ}$ E. Bull. Japan Soc. Fish. Oceanogr., Special Number (Prof. Uda's Commemorative Papers), 91-98.

Morris, M., D. Roemmich, and B. Cornuelle, 1996: Observations of variability in the South Pacific subtropical gyre. J. Phys. Oceanogr., 26, 2359-2379.

Morrow, R. A., R. Coleman, J. A. Church, and D. B. Chelton, 1994: Surface eddy momentum flux and velocity variance in the Southern Ocean from Geosat altimetry. J. Phys. Oceanogr., 24, 2050-2071.

Pedlosky, J., 1987: Geophysical Fluid Dynamics. Springer-Verlag, $710 \mathrm{pp}$.
, L. J. Pratt, M. A. Spall, and K. R. Helfrich, 1997: Circulation around islands and ridges. J. Mar. Res., 55, 1199-1251.

Qiu, B., 1999: Seasonal eddy field modulation of the North Pacific Subtropical Countercurrent: TOPEX/Poseidon observations and theory. J. Phys. Oceanogr., 29, 2471-2486.

— the South Pacific Ocean. J. Phys. Oceanogr., 34, 1515-1527.

Ridgway, K. R., and J. R. Dunn, 2003: Mesoscale structure of the mean East Australian Current system and its relationship with topography. Prog. Oceanogr., 56, 189-222.

— — - and J. L. Wilken, 2002: Ocean interpolation by weighted least squares-Application to the waters around Australia. J. Atmos. Oceanic Technol., 19, 1357-1375.

Roemmich, D., and B. Cornuelle, 1990: Observing the fluctuations of gyre-scale ocean circulation: A study of the subtropical South Pacific. J. Phys. Oceanogr., 20, 1919-1934.

- and J. Gilson, 2001: Eddy transport of heat and thermocline waters in the North Pacific: A key to interannual/decadal climate variability? J. Phys. Oceanogr., 31, 675-687.

Sherman, J., R. E. Davis, W. B. Owens, and J. Valdes, 2001: The autonomous underwater glider "Spray." IEEE J. Oceanic Eng., 26, 437-446.

Stanton, B., D. Roemmich, and M. Kosro, 2001: A shallow zonal jet south of Fiji. J. Phys. Oceanogr., 31, 3127-3130.

Wajsowicz, R. C., 1993: The circulation of the depth-integrated flow around an island with application to the Indonesian Throughflow. J. Phys. Oceanogr., 23, 1470-1484.

Webb, D. J., 2000: Evidence for shallow zonal jets in the South Equatorial Current region of the southwest Pacific. J. Phys. Oceanogr., 30, 706-720.

Wentz, F. J., C. Gentemann, D. Smith, and D. Chelton, 2000: Satellite measurements of sea surface temperature through clouds. Science, 288, 847-850. 